\title{
A randomized study to compare biodegradable self-reinforced polyglycolic acid spiral stents to suprapubic and indwelling catheters after visual laser ablation of the prostate
}

\section{Petas, Anssi}

\section{7}

Petas , A , Talja , M , Tammela , T , Taari , K, Lehtoranta , K, Välimaa , T \& Törmälä , P 1997 , ' A randomized study to compare biodegradable self-reinforced polyglycolic acid spiral stents to suprapubic and indwelling catheters after visual laser ablation of the prostate ' , Journal of Urology , vol. 157 , pp. 173-176 . https://doi.org/10.1016/S0022-5347(01)65316-3

http://hdl.handle.net/10138/297737

https://doi.org/10.1016/S0022-5347(01)65316-3

publishedVersion

Downloaded from Helda, University of Helsinki institutional repository.

This is an electronic reprint of the original article.

This reprint may differ from the original in pagination and typographic detail.

Please cite the original version. 


\title{
A RANDOMIZED STUDY TO COMPARE BIODEGRADABLE SELF- REINFORCED POLYGLYCOLIC ACID SPIRAL STENTS TO SUPRAPUBIC AND INDWELLING CATHETERS AFTER VISUAL LASER ABLATION OF THE PROSTATE
}

\author{
ANSSI PÉTAS, MARTTI TALJA, TEUVO TAMMELA, KIMMO TAARI, KARI LEHTORANTA, \\ TERO VÄLIMAA AND PERTTI TÖRMÄLÄ
}

From the Department of Urology, Helsinki University Central Hospital, Helsinki, Department of Surgery, Päijät-Häme Central Hospital, Lahti, and Division of Urology, Tampere University Hospital and Institute of Biomaterials, Tampere University of Technology, Tampere, Finland

\section{ABSTRACT}

Purpose: A randomized controlled study was done to evaluate the efficacy of the self-reinforced polyglycolic acid spiral stent compared to a suprapubic catheter, and combined suprapubic and indwelling catheters in the prevention of urinary retention after visual laser ablation of the prostate.

Materials and Methods: We studied 72 men with benign prostatic hyperplasia who underwent placement of a suprapubic catheter and visual laser ablation of the prostate. In 27 men in group 1 the self-reinforced polyglycolic acid spiral stent was inserted into the prostatic urethra after visual laser ablation of the prostate, while 23 in group 2 received no other devices. In 22 men in group 3 an indwelling catheter was left in situ for an average of 6.5 days.

Results: Voiding began 1 or 2 days postoperatively in 20 of 27 patients (median 1 day) in group 1 , and 8 of 23 (median 6 days) in group 2 . In 16 of 22 men in group 3 voiding began 1 or 2 days (median 6) after removal of the indwelling catheter. Improvements in patient weighted symptom score, mean peak urinary flow rate and post-void residual volume were significant $(p<0.001)$ at 6 months of followup in all groups. The overall infection rate was $30 \%$.

Conclusions: The self-reinforced polyglycolic acid spiral stent is superior to the suprapubic catheter alone, and to combined indwelling and suprapubic catheters for the treatment of postoperative urinary retention after laser therapy, offering possibilities for shorter catheterization time.

KEY WORDS: biodegradation, laser surgery, prostate, prostatic hypertrophy, stents

Benign prostatic hyperplasia (BPH) is a common phenomenon in aging men. For more than 60 years transurethral electroresection of the prostate has been the gold standard for treatment of bladder outlet obstruction secondary to BPH. However, this procedure requires much experience and the complication rate has remained relatively constant during the last 30 years. ${ }^{1}$ The American Urological Association cooperative study has shown an $18 \%$ immediate postoperative morbidity rate with a perioperative mortality rate of $0.2 \% .^{2}$ For these reasons there has been interest in development of minimally invasive approaches to treat $\mathrm{BPH}$.

Visual laser ablation of the prostate, an alternative treatment of BPH, was first described for clinical use in Australia in $1992 . .^{3}$ Therapy is based on photothermal coagulation of the prostate tissue with a neodymium:YAG laser and a rightangle, side firing, free beam delivery system. However, several problems are associated with visual laser ablation of the prostate, including postoperative urinary retention due to burn edema and the need for prolonged urinary catheterization in up to $38 \%$ of patients. ${ }^{4}$

In 1980 Fabian introduced a urological spiral to keep the prostatic lobes from compressing the urethra, thus allowing for spontaneous voiding. ${ }^{5}$ Others have reported good results with similar spirals for transient or definitive therapy of prostatic obstruction.6,7 In the early 1990s ultrahigh strength, self-reinforced, biodegradable, polymeric composites were developed for tissue management. ${ }^{8}$ Self-reinforced,

Accepted for publication July 26, 1996. poly-l-lactide spirals showed good biocompatibility in the anterior urethra. ${ }^{9}$ Self-reinforced polyglycolic acid and polylactic acid rods have also been used for 10 years for fixation of bone fractures with favorable results. ${ }^{10}$ In 1995 we introduced a biodegradable self-reinforced polyglycolic acid spiral stent that prevented urinary retention after visual laser ablation of the prostate. "The hypothesis for the present study was that suprapubic or indwelling catheterization time after visual laser ablation of the prostate can be shortened with use of a biodegradable spiral stent. A randomized controlled study was done to evaluate the efficacy of the self-reinforced polyglycolic acid spiral stent compared to a suprapubic catheter, and combined suprapubic and indwelling catheters for prevention of urinary retention after visual laser ablation of the prostate.

\section{MATERIALS AND METHODS}

Spiral stent. The self-reinforced polyglycolic acid spiral stent used was manufactured by extrusion and die drawing, ${ }^{8}$ with a wire diameter of $1.1 \mathrm{~mm}$. and a draw ratio of 4 (see figure). In configuration, the device resembled the stent described by Fabian. ${ }^{5}$ The spiral was $8 \mathrm{~mm}$. in diameter and, in the prostatic portion, $45 \mathrm{~mm}$. long. The wire tended to straighten so that during 14 days the outer diameter increased by $64 \%$. The catheter was composed of biocompatible material that degraded in vitro into glycolic acid, mainly by hydrolysis. ${ }^{12}$ Some enzymes in vivo as well as elevated in vitro temperature have been found to accelerate degradation. 


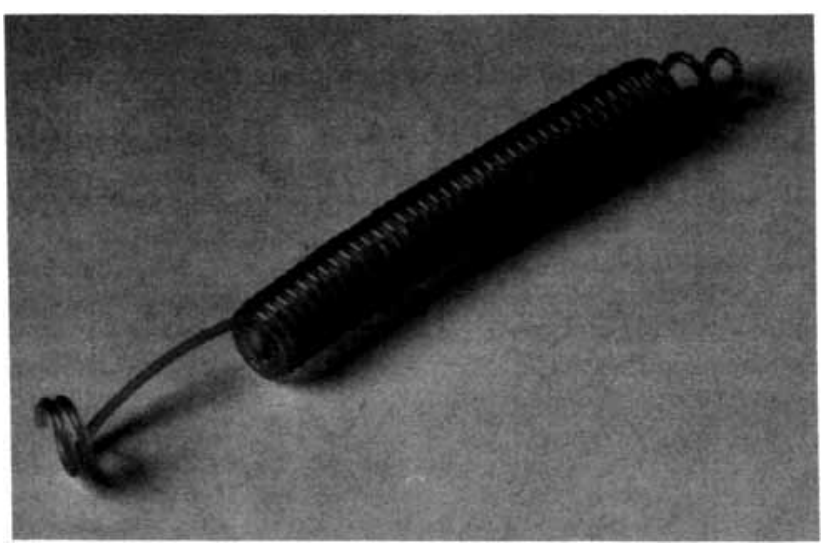

Spiral stent of $1.1 \mathrm{~mm}$. self-reinforced polyglycolic acid wire with $8 \mathrm{~mm}$. outer diameter, $45 \mathrm{~mm}$. diameter of prostatic portion and 75 mm. total length.

The end products of the degradation are water and carbon dioxide. ${ }^{13,14}$ The mechanical properties and degradation time depend on the degree of polymerization, the internal arrangement of the material components, site of implantation and shape of the implant. The spirals were sterilized with ethylene oxide.

Patients. A total of 72 patients 52 to 83 years old (mean age 68.5) with symptomatic BPH entered the study. Patients with malignancy of the bladder or prostate, chronic bacterial prostatitis, urethral stricture or previous surgery of the prostate, as well as therapy with cholinergic or anticholinergic drugs, or finasteride were excluded from the study. Peak urinary flow rate was less than $15 \mathrm{ml}$. per second with a voided volume of more than $150 \mathrm{ml}$.

The patients were randomized into 3 groups: group 1-27 in whom a self-reinforced polyglycolic acid spiral stent was inserted after laser therapy, group $2-23$ who received only the suprapubic catheter after laser therapy and group 3-22 in whom a $20 \mathrm{Ch}$. silicone indwelling catheter was inserted in addition to a suprapubic catheter. All patients received a 12 Ch. suprapubic balloon catheter at cystoscopy before laser therapy, which was removed when the patient was able to void. Three patients in group 1, 2 in group 2 and 1 in group 3 had urinary retention. Ultrasound guided biopsies were obtained if prostate specific antigen was greater than 4.0 ng. $/ \mathrm{ml}$, or digital rectal examination or transrectal ultrasound indicated abnormality. Mean prostatic weight was 46 gm. (range 19 to 90 ) in group $1,40 \mathrm{gm}$. (range 17 to 91) in group 2 and $41 \mathrm{gm}$. (range 16 to 77 ) in group 3 .

Visual laser ablation of the prostate and application of the self-reinforced polyglycolic acid spiral stent. A standard technique for visual laser ablation of the prostate was used with a side firing fiber. Standard neodymium:YAG generators were used to deliver photothermal energy. The power setting was $\mathbf{4 0}$ to 50 watts for 90 seconds for the lateral lobes and 45 seconds for the median lobe. Laser energy was delivered to the lateral lobes in 4 quadrants circumferentially at the 2, 4, 8 and 10 o'clock positions in 2 planes when the prostatic urethra was longer than $2.5 \mathrm{~cm}$. In addition, a slow painting technique was used for additional lasing to achieve total bleaching of the surface of the lateral lobes. After removal of the laser fiber a $5 \mathrm{Ch}$. ureteral catheter was inserted through the cystoscope into the bladder, and the cystoscope was removed. With the tip of the cystoscope a self-reinforced polyglycolic acid spiral stent was pushed into the prostatic urethra along the ureteral catheter. The correct location of the stent was verified endoscopically. The patients were allowed to void immediately and voiding ability was recorded. The suprapubic catheter was removed when the patient was able to void freely, and the patient was discharged from the hospital.

Followup. Followup studies consisted of uroflowmetry; ultrasonic estimation of post-void residual urine; analysis of serum creatinine, c-reactive protein and urine culture; a patient weighted symptom score questionnaire (DAN-PSS-1, including questions addressing sexual problems), ${ }^{15}$ and urethrocystoscopy. The studies were performed preoperatively, and at 4 weeks, and 3 and 6 months after visual laser ablation of the prostate. Transrectal ultrasound was also performed at 6 months.

Statistics. The paired Student $t$ test was used to evaluate differences among the time points. The chi-square test was used to evaluate the beginning of voiding. A value of $p<0.05$ was considered statistically significant.

\section{RESULTS}

All but 1 patient completed 6 months of followup. The mean dose of laser energy used was 957 (range 367 to 2,188), 950 (range 573 to 2,074) and 983 (range 554 to 2,270 ) J./gm. in groups 1,2 and 3 , respectively. Of the 27 patients in group 1,20 voided freely on postoperative day 1 or 2 compared to 8 of 23 in group $2(p<0.001)$. The mean prostatic size was 53 gm. (range 26 to 83 ) in 7 patients with delayed voiding in group 1 , of whom 2 had urinary retention preoperatively and at 1 month of followup. Mean prostatic size did not differ significantly $(p<0.34)$ from that of patients with free postoperative voiding. In group 3 the indwelling catheter was removed at an average of 6.5 days, after which 16 of 22 patients were able to void within 2 days.

In group 1 bleeding from the prostate during laser therapy caused blood clots postoperatively and delayed voiding in 1 patient. In 2 patients the spiral stent was pushed proximally because of placement too distally: 1 had urinary leakage and 1 had urinary retention. One patient had a thin, membranelike stricture at the external sphincter area at 1 month of followup, which was treated with internal urethrotomy and no further strictures occurred. In 1 patient a suprapubic catheter was reinserted for 7 days because of preperitoneal urine leakage after removal of the initial catheter. Four patients in group 4 who had postoperative urinary retention (range 4 to 29 days) were treated after the beginning of voiding and removal of the suprapubic catheter. Transurethral incision of the prostate was performed 3 months postoperatively in 1 of these patients because of stricture of the bladder neck.

In group 3 there were 2 cases of urinary retention at 10 days and 2 months postoperatively, which also included hemorrhage requiring bladder irrigation. Also, 1 patient had stricture at the external sphincter area 3 months postoperatively, which was treated by intermittent urethrotomy and self-dilation.

Peak urinary flow rates increased highly significantly during the 6 months of followup ( $p<0.001$, see table) in all groups, whereas such improvement was already significant at 1 month in groups 1 and 2 but not in group 3 . At 6 months peak flow urinary rates were significantly higher in groups 1 and 2 than 3 ( $p<0.05$ ). The difference between peak urinary flow rates in groups 1 and 2 was not significant at 6 months. Mean residual urine decreased from 164 to 40 ( $p<0.01$ ), 139 to $40(p<0.001)$ and 138 to $40(p<0.01) \mathrm{ml}$. in groups 1 to 3 , respectively, at 6 months. The patient weighted prostatic symptom score decreased highly significantly at 6 months of followup ( $p<0.001$ ) in every group. There were no significant differences in symptom scores between the groups at 6 months. There was no significant change in sexual symptom score in any group.

Group 1 patients stated that voiding was unobstructed during the first 3 weeks postoperatively. Thereafter, some patients experienced diminished stream force and increased 


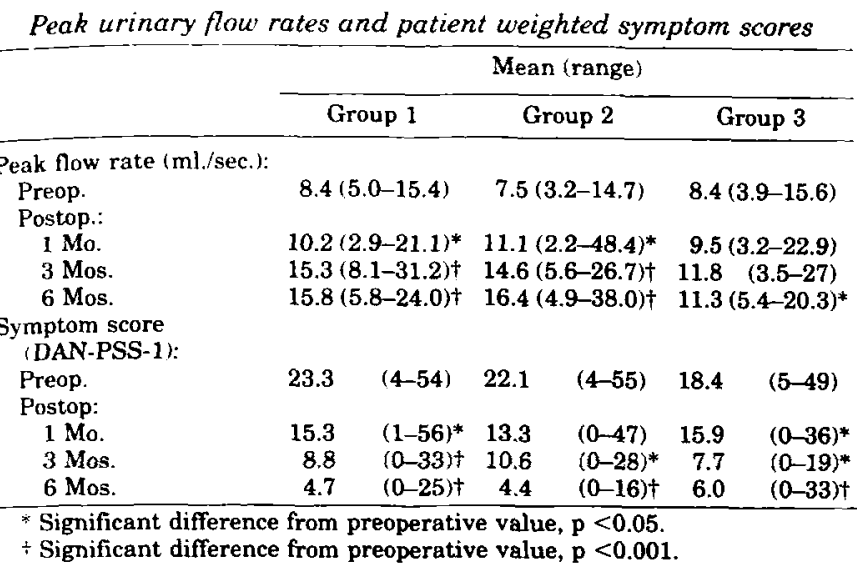

obstructive symptoms for several weeks. This increase in symptoms fits well with the degradation time of the selfreinforced polyglycolic acid spiral stent as evaluated by urethroscopy. At 4 weeks patients still had some spiral stent fragments in the posterior urethra. No foreign bodies or urinary stones were noted in the bladder at 3 or 6 months. The entire prostatic urethra was lined with necrotic tissue 4 weeks postoperatively in all patients. At 3 months half of the lased prostatic surface was still covered with necrotic tissue, and a third of the patients still had a few small necrotic areas in the prostatic urethra at 6 months after visual laser ablation of the prostate.

No blood transfusions were required. Urine culture was positive 4 weeks postoperatively in 6 patients in group 1,7 in group 2 and 7 in group 3 , and remained positive at 3 months in 2,2 and 3 , respectively. Postoperative infections occurred during followup in 7 of 27 patients (26\%) in group 1, 8 of 23 (35\%) in group 2 and 8 of $22(36 \%)$ in group 3 . The overall infection rate was $30 \%$. The infection rates among the treatment groups were not significantly different. However, all urinary tract infections occurred in patients with more than 4 days of suprapubic catheterization.

\section{DISCUSSION}

Laser therapy induces a high temperature in prostatic tissue causing acute tissue swelling due to burn edema, which tends to obstruct the prostatic urethra and cause transient urinary retention. This retention is conventionally prevented by use of an indwelling or suprapubic catheter. However, there is no consensus as to when the catheter should be removed. Intervals of 24 hours to 7 days have been recommended.4,16, 17 Prolonged indwelling or suprapubic catheterization after visual laser ablation of the prostate is inconvenient for the patient, and the suprapubic and indwelling catheters provide a route for bacterial infection into the bladder. ${ }^{18}$ Bacterial contamination of the necrotic prostatic tissue may even lead to prolonged urinary infection. After laser prostatectomy infection rates of up to $30 \%$ have been reported. 19,20 In our study the incidence of postoperative infections was significantly lower during the short 1 to 2-day catheterization period, which suggests that infections associated with visual laser ablation of the prostate are due to catheter contamination and migrating infection. With the spiral stent we can decrease effectively the incidences of postoperative urinary retention and infection, both of which are common complications of laser therapy.

In 1995 Talja et al introduced a new biodegradable selfreinforced-polyglycolic acid spiral stent, with which urinary retention after visual laser ablation of the prostate can be prevented.11 There is no need to remove the device later because the spiral stent degrades into small fragments of polymer debris that are excreted with the urine. In practice, most of our patients did not notice softened debris in the urine. Any polymer fragments remaining in the bladder will degrade completely within a few weeks without stone formation. In previous experimental studies we have shown that biodegradable materials are biocompatible in the anterior urethra. Spirals made of self-reinforced polylactic acid induced less incrustation and inflammation in the urethra than did stainless steel spirals. ${ }^{9}$

Some of our patients in the spiral stent group noticed that voiding became more obstructed at 3 to 4 weeks postoperatively, which was probably due to the degradation and sloughing of the spiral stent. At that time edema and necrotic debris still obstructed the prostatic urethra. However, the obstructive symptoms decreased to a similar level at 4 weeks of followup in all patients. This transient voiding problem might be avoided with use of a spiral stent with a longer degradation time of up to several months, achieved by selecting more slowly degrading molecules.

Thus, the outcome of visual laser ablation of the prostate in our study was in line with the results reported by others, 4,16,17 Overall, the decrease in voiding symptoms was highly significant. The patient weighted symptom score was useful in our study, since it also included a bother score and, therefore, is considered to provide a more reliable estimate of symptoms than do other scoring systems. ${ }^{15}$ Mean laser energy in our study was $963 \mathrm{~J} . / \mathrm{gm}$., compared to $656 \mathrm{~J} / \mathrm{gm}$. in our previous study, ${ }^{11}$ which we believe indicates improved overall results. Energy levels of 1,000 to 2,000 J./gm. or more have been recommended. ${ }^{21}$ There was no late urinary retention in the spiral stent group during followup. Despite the greater energy dose, much adenoma remained on cystoscopic examination in many patients at 6 months. Improvement in peak urinary flow rates was greater in groups 1 and 2 than in group 3. However, there were no significant differences in baseline parameters, laser therapy, infection rate or additional procedures.

\section{CONCLUSIONS}

Although visual laser ablation of the prostate offers some advantages over transurethral electroresection of the prostate, including a faster and safer procedure as well as shorter hospitalization, the burn-like edema produced after lasing means that a catheter or other device is required to prevent urinary retention. The biodegradable self-reinforced polyglycolic acid spiral stent is a novel method of preventing urinary retention after visual laser ablation of the prostate. Use of this device decreases the need for catheterization. The spiral stent has also been used with good results to prevent urinary retention after microwave therapy at a high energy setting. ${ }^{22}$ The spiral stent might be effective in treatment modalities after other BPH therapies that might induce edema, such as transurethral needle ablation of the prostate, high intensity focused ultrasound, interstitial laser coagulation of the prostate and cryotherapy. Other indications for the spiral stent might be recurrent bladder neck strictures and temporary treatment of patients with urinary retention who are awaiting surgery. However, further controlled studies are needed to compare the spiral stent to other methods of preventing urinary retention. Spiral stents with a shorter expansion time, various degradation times and configurations are also issues of further interest.

\section{REFERENCES}

1. Garraway, W. M., Collins, G. N. and Lee, R. J.: High prevalence of benign prostatic hypertrophy in the community. Lancet, 338: 469, 1991.

2. Mebust, W. K., Holtgreve, H. L., Cockett, A. T. K. and Peters, P. C. Transurethral prostatectomy: immediate and postoperative complications. A cooperative study of 13 participating institutions in evaluating 3,885 patients. J. Urol., 141: 243, 1989. 
3. Costello, A. J., Bowsher, W. G., Bolton, D. M., Braslis, K. G. and Burt, J.: Laser ablation of the prostate in patients with benign prostatic hypertrophy. Brit. J. Urol., 69: 603, 1992.

4. Norris, J. P., Norris, R. D., Lee, R. D. and Rubenstein, M. A.: Visual laser ablation of the prostate: clinical experience in 108 patients. J. Urol., 150: 1612, 1993.

5. Fabian, K. M.: Der intraprostatische "partielle Katheter" (urologische Spirale). Urologe A, 19: 236, 1980

6. Nordling, J., Holm, H. H., Klarskov, P., Nielsen, K. K and Andersen, J. T.: The intraprostatic spiral: a new device for insertion with the patient under local anesthesia and with ultrasonic guidance with 3 months of followup. J. Urol., 142: 756,1989

7. Ala-Opas, M., Talja, M., Titinen, J., Hellström, P., Heikkinen, A. and Nurmi, M.: Prostakath in urinary outflow obstruction. Ann. Chir. Gynaec., suppl., 206: 14, 1993.

8. Törmälä, P.: Biodegradable self-reinforced composite materials; manufacturing structure and mechanical properties. Clin. Mater., 10: 29, 1992.

9. Kemppainen, E., Talja, M., Riihelä, M., Pohjonen, T., Törmälä, $P$, and Alfthan, O.: A bioresorbable urethral stent. An experimental study. Urol. Res., 21: 235, 1993.

10. Rokkanen, P., Böstman, Ö., Vainionpää, S., Vihtonen, K., Törmälä, P., Laiho, J., Kilpikari, J. and Tamminmäki, M.: Biodegradable implants in fracture fixation: early results of treatment of fractures of the ankle. Lancet, 1: 1422, 1985.

11. Talja, M., Tammela, T., Pétas, A., Välimaa, T., Taari, K. Viherkoski, E. and Törmälä, P.: Biodegradable self-reinforced polyglycolic acid spiral stent in prevention of postoperative urinary retention after visual laser ablation of the prostatelaser prostatectomy. J. Urol., 154: 2089, 1995.

12. Chu, C. C.: Hydrolytic degradation of polyglycolic acid: tensile strength and crystallinity study. J. Appl. Polym. Sci., 26: 1727, 1981 .
13. Williams, D. F. and Mort, E.: Enzyme-accelerated hydrolysis of polyglycolic acid. J. Bioeng., 1: 231, 1977.

14. Chu, C. C. and Williams, D. F.: The effect of gamma irradiation on the enzymatic degradation of polyglycolic acid absorbable sutures. J. Biomed. Mater. Res., 17: 1029, 1983

15. Meyhoff, H. H., Hald, T., Nordling, J., Andersen, J. T., Bilde, T. and Walter, S.: A new patient weighted symptom score system (DAN-PSS-1). Clinical assessment of indications and outcomes of transurethral prostatectomy for uncomplicated benign prostatic hyperplasia. Scand. J. Urol. Nephrol., 27: 493, 1993.

16. Kabalin, J. N.: Laser prostatectomy performed with a right angle firing neodymium:YAG laser fiber at $\mathbf{4 0}$ watts power setting. J. Urol., 150: 95, 1993.

17. Costello, A. J., Schaffer, B. S. and Crowe, H. R.: Secondgeneration delivery systems for laser prostatic ablation. Urology, 43: 262, 1994.

18. Nickel, J. C., Grant, S. K and Costerton, J. W.: Catheter associated bacteriuria. Urology, 26: 369, 1985

19. Boon, T. A., de Gier, R. P. E., van Venrooij, G. E. P. M., van Swol, C. F. P. and Verdaasdonk, R. M.: Clinical and urodynamic results six months after "TULIP" laser prostatectomy. In: Proceedings of the XIth Congress of the European Association of Urology, abstract 149, July 13-16, 1994.

20. le Rolland, B., Barthelemy, Y., Colombel, M., Chopin, D. and Abbou, C. C.: TULIP laser in the treatment of benign hypertrophy of the prostate (BPH). In: Proceedings of the XIth Congress of the European Association of Urology, abstract 152, July 13-16, 1994.

21. Kabalin, J. N.: Laser prostatectomy-what we have accomplished and future directions. J. Urol., 154: 2093, 1995.

22. Dahlstrand, C., Grundtman, S. and Petterson, S.: The use of resorbable stents to avoid catheterization after high energy TUMT for large, symptomatic, benign prostatic hyperplasia. Scand. J. Urol. Nephrol., suppl., 169: 51, 1995. 